\title{
The Increasing Trend of Black Carbon and Carbon Dioxide During 1990 -2018 in the Atmosphere of North Jordan and its Association with the Energy Balance and the Increase of the Temperature and Climate Change
}

\author{
Ahmed H Al Alawneh and Khadeejeh M Hamasha* \\ Department of Physics, Yarmouk University, Jordan
}

Submission: October 27, 2021; Published: November 12, 2021

*Corresponding author: Khadeejeh M Hamasha, Department of Physics, Yarmouk University, Jordan

\begin{abstract}
Sun is the main source of energy on earth. Part of the solar radiation that reaches the top of the atmosphere reflects back to space, while the other part undergoes processes in the layers of the atmosphere and the rest reaches the surface of the earth. The radiation that reaches the surface of the earth will undergo reflection and absorption. The absorbed parts will be re-emitted as sensible heat and latent heat. Near the earth's surface, the energy flux of incoming radiation is supposed to equal the energy flux of outgoing radiation to keep the average temperature of the earth constant. The energy budget near the surface of the earth is the difference between the incoming energy and the outgoing energy. The surface energy budget is calculated for the period between 1990 and 2018 using satellite data in north Jordan. The energy budget near the surface of the earth in north Jordan shows an increasing trend for the period of 1990 to 2018 with linear regression of slope equal to 8.7 (mW/ $\left.\mathrm{m}^{2}\right) / \mathrm{yr}$ and R2 $=0.56$. This imbalance in the budget is caused by many factors that increase heat absorption in the atmosphere. Black carbon and carbon dioxide are the most radiation absorbers in the atmosphere. Black carbon mass concentration during the period 1990 - 2018 shows an increasing trend with linear regression of slope equals to $0.78\left(\mathrm{ng} / \mathrm{m}^{3}\right) / \mathrm{yr}$ and $\mathrm{R}^{2}=0.82$. Also, Carbon dioxide shows an increasing trend with linear regression equals to $2.15 \mathrm{ppm} / \mathrm{yr}$ and $\mathrm{R}^{2}=0.99$. And as expected the average surface temperature shows an increasing trend because of the imbalance in the energy budget. The average temperature in north Jordan was increasing with linear regression of slope equals to $0.0539 \mathrm{yr} /$ ${ }^{\circ} \mathrm{C}$ and $\mathrm{R}^{2}=0.51$. The average temperature change in the period of study was $1.51^{\circ} \mathrm{C}$, which is consistent with global warming and associated with the increasing trend of black carbon and carbon dioxide. And this increase in temperature leads to climate change.
\end{abstract}

Keywords: Energy balance; Carbon dioxide; Black carbon; Air pollution; Increasing temperature; Climate change

\section{Introduction}

Systems on the surface of the earth are often described with a budget, including the energy system. The energy budget is described as an analysis of the distribution of solar radiation in the earth system, based on the amount of solar radiation entering the earth, the amount of radiation absorbed by clouds and aerosols, and the amount of radiation reflected to space [1]. The sun is the main energy source on earth, through solar radiation that gives light and heat. The total solar energy at an average distance from the earth can be expressed by the total solar radiation, which is about $1367 \mathrm{~W} / \mathrm{m}^{2}$. According to the basic geometry of the earth, the amount of this energy decreases by half because only half of the sphere is exposed to radiation. In the other hand, the angle of the radiation changes with latitude, and with the change of the radiation angle, the amount of radiation also decreases by an additional half, which means that the amount of radiation that reaches the surface of the earth is only a quarter of the total sunlight radiation, $340 \mathrm{~W} / \mathrm{m}^{2}$, but this amount is not constant in all regions, it varies according to place and time [2]. When solar radiation enters earth, a group of major processes occurs, the most important of which are absorption, emission, and dispersion. During the absorption process, a decrease in the 
energy available at the earth's surface occurs through molecules in the atmosphere such as water vapor and carbon dioxide in the visible radiation range, and ozone molecules in the ultraviolet radiation range [3]. Regarding the dispersion process, there are two types; the first type is when a solar beam of wavelengths in the range of $380-780 \mathrm{~nm}$ diffuses by particles of sizes much smaller than the wavelength of radiation. The second type is due to the presence of molecules that have approximately the same dimension as wavelength or larger such as water droplets and ice crystals, but this type depends on local weather conditions such as air pollution and clouds [4]. Most of the radiation is reflected directly from the atmosphere, especially from clouds, due to some atmospheric processes. The remaining amount of radiation reaches the earth through direct radiation. The earth absorbs most of the radiation while the other part reflects what is known as reflection or albedo. The albedo depends on the geographical location and surface characteristics of the earth with an average value of 0.3 , which means that the earth absorbs about 0.7 of the radiation. The earth's absorption of this radiation raises its temperature just like a black body [5]. All hot objects emit electromagnetic radiation, especially if they are surrounded by space. This radiation is considered to be an emitted radiation, and when the incoming radiation is greater than the emitted radiation, the heating process will continue, leading to a continuous increase in the temperature of the radiated object. The body will keep emitting radiation until radiation balance is achieved, according to Stefan Boltzmann's law. The largest part of emitted energy from the earth is returned to earth again, and the rest of it is transferred to space. The amount of energy that is returned is the sum of what is reflected by clouds, and atmospheric radiation [6].

The importance of the energy budget is to determine the climate and weather through the coming amount of radiation and its distribution, since the earth system is considered one of the most important solar energy systems. The absorbed radiation heats the surface of the earth, and pushes the processes of photosynthesis, evaporation of fuel and melting snow and ice. Any change in the distribution, transfer, or

transformation of energy causes imbalance. This imbalance leads to various weather phenomena or atmospheric disturbances, such as high temperatures, melting glaciers and some other strange phenomena that the world has experienced in the recent period. This disturbance in the distribution of energy in various ways leads to global warming [7] and climate change. The energy imbalance at the surface of the earth is associated with the increase of carbon dioxides [8] and aerosols [9] such as black carbon in the atmosphere.

\section{Surface Energy Budget (SEB)}

The surface of the earth is the boundary between the earth and the atmosphere, where energy exchange processes occur. These processes are important in determining the climate and balancing the energy at the surface, which is determined by the energy flows. The surface characteristics are important in determining the energy balance and the most important of these characteristics is the ground albedo, $\alpha_{\mathrm{p}}$. The surface energy budget (SEB) is given by:

$$
S E B=\left|R_{n}-(L H+S H)\right|
$$

Where is the net radiation, $\mathrm{LH}$ is the latent heat flow and $\mathrm{SH}$ is the sensible heat. Note that in the case of equilibrium, the SEB is equal to zero. Latent heat flow ( $\mathrm{LH})$ is the heat that accompanies the transformation of a substance from one state to another, for example, the process of transformation from a liquid state to a gaseous state. In the energy balance it expresses the energy that is absorbed or released by the surface through the process of evaporation. Sensible heat ( $\mathrm{SH}$ ) is the energy required to change a substance's temperature without changing its phase from one state to another in the reasonable temperature, which differs from the latent heat in which a change in the state of the substance occurs without changing its temperature. The temperature changes as a result of the absorption of the air or the surface of solar radiation. Equation (1) expresses SEB through the net inputs of short and long radiation minus the latent and sensible heat that flows through the surface by the processes of evaporation and convection.

Globally, average available solar radiation in the upper part of the atmosphere is about $342 \mathrm{~W} / \mathrm{m}^{2}$. The planet absorbs about $70 \%$ of the incident solar radiation and reflects about $30 \%$. About $50 \%$ of the insolation available in the upper part of the atmosphere reaches the surface and is absorbed there. In the stratosphere $3 \%$ of insolation is absorbed due to ozone and molecular oxygen, while carbon dioxide and water vapor contribute about $0.5 \%$. The $17 \%$ absorption of sun's radiation in the troposphere is mainly due to: water vapor $(13 \%)$, carbon dioxide $(3 \%)$, while ozone and oxygen together contribute to the remaining (1\%). The total amount of energy absorbed from the earth system is the sum of $50 \%$ of the energy absorbed at the surface and $20 \%$ absorbed in the atmosphere. The rest corresponds to the terrestrial albedo, whose average value is estimated as $30 \%$, representing the radiation reflected from the surface of the earth. The net short wave depends on the amount of sunlight absorbed by the surface of the earth $\left(S_{\text {down }}\right)$ and the amount of short wave that the surface emits $\left(S_{u p}\right)$. Since the earth does not emit short wave on its surface, the net flux of short wave, on the surface is only what is absorbed by the surface, which can be written as the following:

$$
\begin{aligned}
& S_{n}=S_{\text {down }}-S_{\text {up }} \\
& S_{n}=S_{\text {down }}
\end{aligned}
$$

Since the amount of the absorbed radiation can be represented by the albedo as the following:

$$
S_{\text {down }}=\left(1-\alpha_{p}\right) \mathrm{S}_{\text {in }}
$$


Where $S$ is the incoming solar radiation, hence the net short radiation can be written as:

$$
S_{n}=\left(1-\alpha_{p}\right) \mathrm{S}_{\text {in }}
$$

When radiation falls on the earth's surface, it is absorbed and hence heats up the surface. Continued heating leads to an increase in temperature, and according to Stephen Boltzmann's law the earth will emit radiation within the long wavelength range $\left(L_{u p}\right)$. This radiation depends mainly on the surface temperature. The emission of this radiation into the atmosphere will be absorbed by gases. The absorbed rays are emitted in all directions until the bulk of them return back to the surface of the earth representing the long radiation falling on the surface of the earth due to greenhouse gases and we will symbolize them by $\left(L_{\text {down }}\right)$. The net radiation of the long wave is expressed by the following equation:

$$
L_{n}=L_{\text {down }}-L_{u p}
$$

Knowing the emissivity, $\epsilon_{s^{\prime}}$ surface temperature, $T_{s}$, and long wave radiation coming from the atmosphere, net flux will be found. When the effective absorption of the surface is equal to the ability of the surface to emit, this equality occurs if the frequencies of the emitted radiation from the surface are equal to the frequencies of the long wave coming from the atmosphere. Then part of the incoming long wave radiation is absorbed on the surface where it can be expressed as outgoing longwave radiation from the surface as:

$$
L_{u p}=\epsilon_{s} \sigma T_{s}^{4}+\left(1-\epsilon_{s}\right) L_{\text {down }}
$$

Where is the Stefan Boltzmann constant and equals to $5.67 \times 10^{-8} \mathrm{~W} \mathrm{~m}^{-2} \mathrm{~K}^{-4}$

$$
\begin{aligned}
& \text { and } \\
& L_{n}=L_{\text {down }}-\left(\in_{s} \sigma T_{s}^{4}+(1-) L_{\text {down }}\right) \\
& L_{n}=\in_{s}\left(L_{\text {down }}-\sigma T_{s}^{4}\right)
\end{aligned}
$$

The surface of the earth is considered to be hotter than the air above it, since the earth is the one that supplies the air with energy, beside the energy is transferred from hot bodies to cold ones. The higher once rise above the ground, the cooler the air because the net long wave radiation on the surface is mostly negative because the amount of radiation emitted from the surface is greater than the amount of radiation gained by the surface from the return radiation, since part of the returning radiation is lost in space. In other cases, the net radiation may be positive if the amount of radiation emitted from the surface is equal to zero, so that the net radiation is equal to the amount of radiation emitted from the air, or if there is a heavy cloud cover that contains good clouds for absorption, the air is colder than the surface or both have the same temperature. From our knowledge of both short and long wave net energy, we can write the net energy at the surface as:

$$
R_{n}=S_{n}+L_{n}
$$

The main equation for the energy balance at the surface becomes:

Surface energy balance $(S E B)=|R n-(L H+S H)|$

\section{Greenhouse Effect}

Greenhouse gases are gases present in the atmosphere in natural proportions characterized by their ability to absorb radiation emitted from the earth, thus reducing the amount of energy wasted in space. Among the most famous gases are carbon dioxide $\left(\mathrm{CO}_{2}\right)$, ozone $\left(\mathrm{O}_{3}\right)$, water vapor, methane $\left(\mathrm{CH}_{4}\right)$, nitrous oxide $\left(\mathrm{N}_{2} \mathrm{O}\right)$ and chlorofluorocarbons (CFCs) [10]. The greenhouse gases play an important role in preserving life on the surface of the earth by maintaining the temperature stable. The absence of these gases will result in a decrease in the earth's temperature. These gases allow short wavelength sunlight to pass through the atmosphere and do not interact with it. Due to the chemical properties of the gases and the earth's absorption of this radiation, earth will emit radiation in the long wavelengths region. These gases absorb long wavelengths and emit back into the atmosphere and leading to an increase in the temperature of the atmosphere, which re-radiate the infrared radiation towards the earth surface, and the continuation of this process traps radiation near the surface of the earth. As the trapped radiation on the earth's surface increases, the earth's temperature increases. This is called the greenhouse gas effect [11]. Ozone $\left(\mathrm{O}_{3}\right)$ absorbs ultraviolet rays and scatters light, hence it removes part of the solar radiation before it reaches the surface of the earth. Water vapor and carbon dioxide are the most important gases that absorb infrared radiation. The atmosphere is transparent to solar radiation compared to the radiation of the earth, for which the atmosphere is opaque. This explains the effect of water vapor and carbon dioxide in absorbing infrared radiation due to the interaction of molecules dipole moments with electromagnetic radiation [12]. For example, in the carbon dioxide molecule, which consists of carbon that has a positive charge and negatively charged oxygen, it has multiple vibration patterns related to specific wavelengths of electromagnetic energy, and these wavelengths are within the infrared radiation. As the absorption of this energy increases the molecules vibrational patterns, this increase appears in the form of thermal energy that increases the temperature of the atmosphere [13] The effect of greenhouse gases and their role can be illustrated through a simple energy balance model, which is used also to determine the emission temperature, where the atmosphere is transparent to the passage of solar radiation, and opaque to other rays. Such as the radiation emitted from the earth, so that the atmosphere absorbs this radiation and raises its temperature. The atmosphere is like a black body that emits radiation, part of it returns to space in this model, and the bulk of the radiation returns to the earth in the form of longwave radiation [14]. 


\section{Measurements}

In this study, the surface energy balance during the period 1990-2018 and its relationship to the carbon dioxide and black carbon has been investigated in northern Jordan, specifically in Irbid city. Irbid is $80 \mathrm{~km}$ north of the capital, Amman and 20 kilometers south of the Syrian border. Irbid has coordinates 32.55
N, 35.85 E. It has the second largest metropolitan population in Jordan after Amman, with a population of around 1,911,600. People of the city gatherings in commercial complexes and malls, besides a large number of cafes and cars that contribute significantly to pollutants in the city's atmosphere. The city of Irbid is characterized by a moderate climate in summer, cold and rainy in winter (Figure 1).

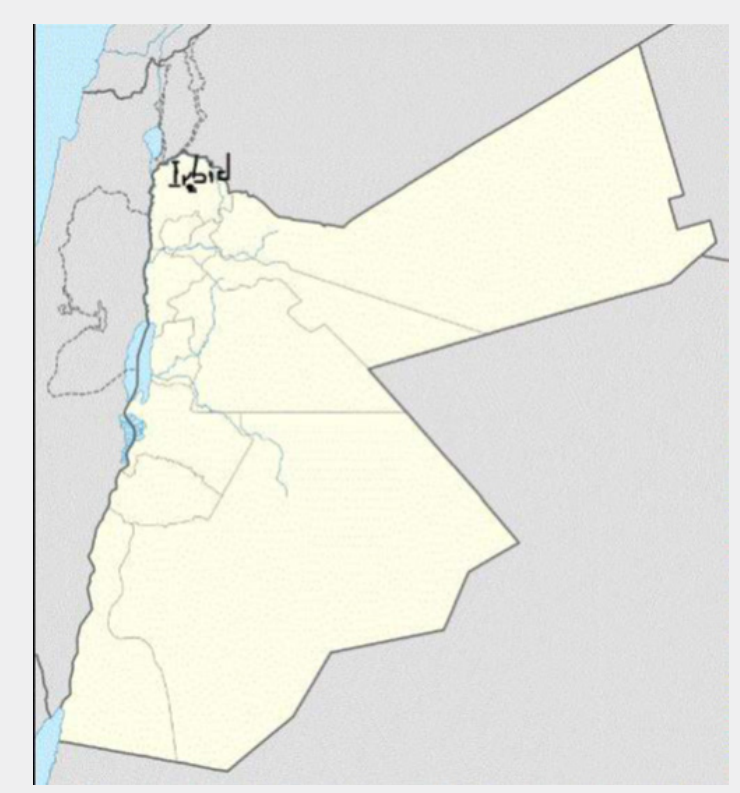

Figure 1: The location of Irbid city, Jordan.

In this study, data were taken from NASA's Giovanni website. This website created by the agency provides a set of variables and geophysical information. Data can be viewed through many NASA satellites that display this data after determining it and choosing the site in terms of determining the latitude and longitude for monitoring information. The most important variables that have been studied are the surface

albedo, long wave radiation absorbed from the surface, incoming short wave radiation at the surface, long wave net flux, incoming short wave radiation, latent heat flow, sensible heat flow, air temperature, carbon dioxide, carbon monoxide, Outgoing long wave radiation, black carbon, and incoming long wave radiation.

\section{The energy budget over time}

The surface energy budget is considered as the magnitude of the difference between the net short and long wavelength radiation and the net sensible heat and latent heat. Table 1 shows the monthly values of the earth's albedo values, the incoming shortwave radiation, the long wavelength emitted radiation, the incoming long wavelength radiation, in addition to latent heat, sensible heat, the net long wavelength radiation and net short wavelength radiation on the surface that were collected in the year 1990. The energy budget for any month can be obtained by taking the absolute value of SEB (eqn. 10).
Monthly SEB values for 1990 are ranged between $0.27 \mathrm{~W} / \mathrm{m}^{2}$ and $1.14 \mathrm{~W} / \mathrm{m}^{2}$ with average value of $0.64 \mathrm{~W} / \mathrm{m}^{2}$.

Annual SEB was obtained for the years from 1990 to 2018 using the same procedure from Giovanni website data for Irbid city and summarized in Table 2 .

The annual SEB have values change between $0.54 \mathrm{~W} / \mathrm{m}^{2}$ and $0.96 \mathrm{~W} / \mathrm{m}^{2}$ with an average value of $0.68 \mathrm{~W} / \mathrm{m}^{2}$. SEB values have an increasing trend over the years as seen from Figure 2.

From Figure 2, SEB is increased with years, and has a linear regression of slope equal to $8.7\left(\mathrm{~mW} / \mathrm{m}^{2} . \mathrm{yr}\right)$ and $\mathrm{R}^{2}=0.56$. This means that there is an imbalance of the surface energy of north Jordan and this imbalance is increased by the time going on.

\section{The average concentration of atmospheric carbon dioxide $\left(\mathrm{CO}_{2}\right)$ in Irbid city during 1990-2018}

Data of carbon dioxide were collected for Irbid city, north Jordan during the time period from 2002-2016 using maps from the Giovanni website. Figure 3 shows the annual average concentrations of atmospheric $\mathrm{CO}_{2}$ in Irbid city. Atmospheric $\mathrm{CO}_{2}$ concentrations have an increasing trend with time with a linear regression of slope equals $1.97 \mathrm{ppm}$ and $\mathrm{R}^{2}=0.995$. Since the proportion of the variance, $\mathrm{R}^{2}$ represents a strong relationship between the atmospheric $\mathrm{CO}_{2}$ concentrations and time; we can 
use this data to estimate data for the periods of 1990 - 2002 and 2016 - 2018. It is clear that the atmospheric $\mathrm{CO}_{2}$ concentration

in Irbid city was increased from 347ppm in 1990 to $408 \mathrm{ppm}$ in 2018, and it is expected to reach $476 \mathrm{ppm}$ by 2050.

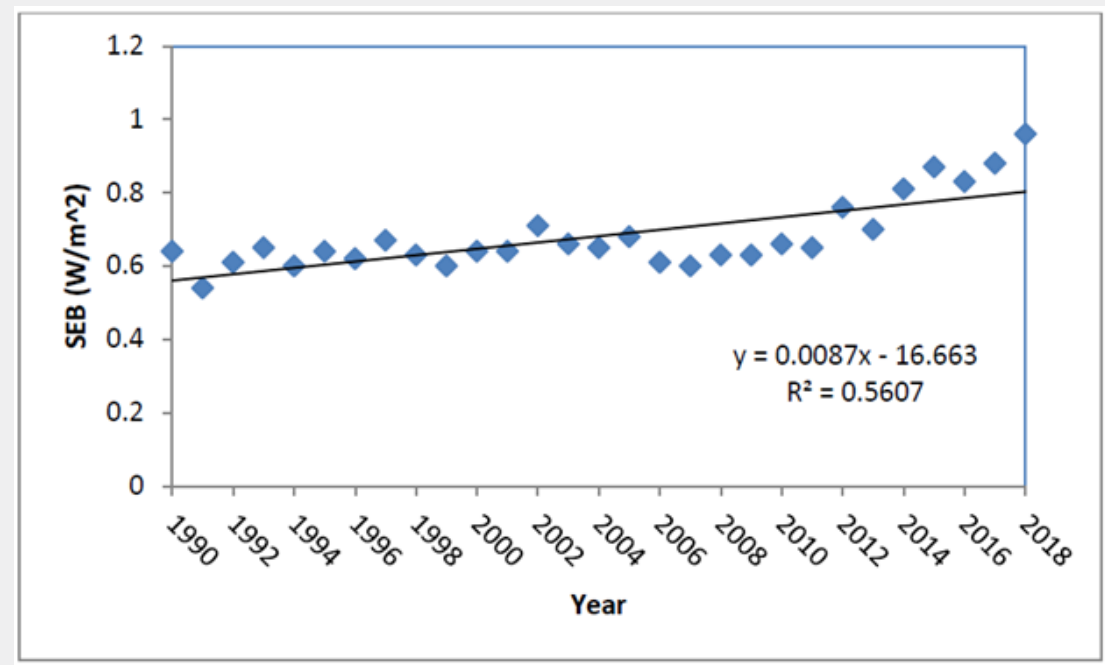

Figure 2: The variation of the annual SEB in north Jordan during the years 1990- 2018.

Table 1: A monthly surface energy budget for Irbid city during the year 1990.

\begin{tabular}{|c|c|c|c|c|c|c|c|c|c|c|}
\hline Month & $\boldsymbol{\alpha}_{\mathbf{p}}$ & $\mathbf{1 - \alpha _ { \mathbf { p } }}$ & $\mathbf{S}_{\text {in }}\left(\mathbf{W} / \mathbf{m}^{2}\right)$ & $\mathbf{S}_{\mathbf{n}}\left(\mathbf{W} / \mathbf{m}^{2}\right)$ & $\begin{array}{c}\mathbf{L}_{\text {down }} \mathbf{( W} / \\
\mathbf{m}^{2} \mathbf{~}\end{array}$ & $\mathbf{L}_{\text {up }}\left(\mathbf{W} / \mathbf{m}^{2}\right)$ & $\mathbf{L}_{\mathbf{n}}\left(\mathbf{W} / \mathbf{m}^{2}\right)$ & $\mathbf{R}_{\mathbf{n}}\left(\mathbf{W} / \mathbf{m}^{2}\right)$ & $\mathbf{S H + L H}\left(\mathbf{W} / \mathbf{m}^{2}\right)$ & $\mathbf{S E B}\left(\mathbf{W} / \mathbf{m}^{2}\right)$ \\
\hline Jan & 0.2993 & 0.7007 & 121.35 & 85.03 & 290.2 & 349.21 & -59.01 & 26.02 & 26.45 & 0.43 \\
\hline Feb & 0.3093 & 0.6907 & 151.87 & 104.9 & 300.5 & 356.26 & -55.76 & 49.14 & 49.49 & 0.35 \\
\hline Mar & 0.3167 & 0.6833 & 233.57 & 159.6 & 297.4 & 372.99 & -75.59 & 84.01 & 84.28 & 0.27 \\
\hline Apr & 0.3198 & 0.6802 & 293.44 & 199.6 & 317.3 & 399.83 & -82.53 & 117.07 & 117.53 & 0.46 \\
\hline May & 0.328 & 0.672 & 354.46 & 238.2 & 323.1 & 426.4 & -103.3 & 134.9 & 135.64 & 0.74 \\
\hline Jun & 0.3309 & 0.6691 & 390.23 & 261.1 & 333.5 & 447.8 & -114.3 & 146.8 & 147.67 & 0.87 \\
\hline Jul & 0.3278 & 0.6722 & 371.62 & 249.8 & 350.3 & 460.2 & -109.9 & 139.91 & 140.91 & 1.01 \\
\hline Aug & 0.3271 & 0.6729 & 344.18 & 231.6 & 347.2 & 458.6 & -111.4 & 120.2 & 121.23 & 1.03 \\
\hline Sep & 0.3254 & 0.6746 & 289.06 & 195 & 344.3 & 446.3 & -102 & 93 & 91.86 & 1.14 \\
\hline Oct & 0.3173 & 0.6827 & 216.79 & 148 & 340 & 433.16 & -93.16 & 54.84 & 55.47 & 0.63 \\
\hline Nov & 0.3017 & 0.6983 & 161.39 & 112.7 & 323.5 & 406.01 & -82.51 & 30.19 & 30.61 & 0.42 \\
\hline Dec & 0.2932 & 0.7068 & 133.66 & 94.47 & 306.1 & 377.98 & -71.88 & 22.59 & 22.88 & 0.29 \\
\hline
\end{tabular}

\section{Black carbon (BC) mass concentration in Irbid city during 1990-2018}

Black carbon (BC) is an aerosol particle formed as a result of the incomplete combustion of fossil fuels and biomass. The presence of $\mathrm{BC}$ in the troposphere leads to global warming similar to carbon dioxide. Data of BC mass concentrations were collected for Irbid city during the time period from 1990-2018 using maps from the Giovanni website and presented graphically in Figure 4. BC mass concentration in the atmosphere of Irbid city has an increasing trend with time. $\mathrm{BC}$ mass concentration has a linear regression with slope equals $7.79 \mathrm{ng} / \mathrm{m}^{3}$.yr and $\mathrm{R}^{2}=0.82$. The increase in the concentration of black carbon has effects on ecosystems by depositing on plant leaves and reducing the photosynthesis process in them. Also it contributes to global warming and raising the temperature because it is effective in absorbing radiation and converting it to heat as well as affects rainfall patterns.

\section{Energy budget and $\mathrm{CO}_{2}$ during 1990-2018}

The relation between carbon dioxide and energy budget over time has been studied and presented in Figure 5. It's clear from Figure 5 that SEB is increasing with increasing concentrations of $\mathrm{CO}_{2}$ in the troposphere because carbon compounds play an 
important role in surface energy balance. $\mathrm{CO}_{2}$ is considered to be one of the most important greenhouse gases, which influence the amount of solar radiation in the troposphere. $\mathrm{CO}_{2}$ is a good absorber for infrared radiation emitted from the surface of the earth and it absorbs radiation in the range from 12-13 micrometers. Moreover, the increase in carbon dioxide concentrations in the atmosphere causes a direct radiative effect on the surface by acting as a closed window that prevents the rays from going out into space and thus returns them to heat the surface of the earth. This means that the earth emits a higher energy than the energy it receives from the long rays. This leads to an imbalance in the net energy, and this explains the link between the increase in carbon dioxide compounds and its relationship to the increase in net energy (Figure 6).

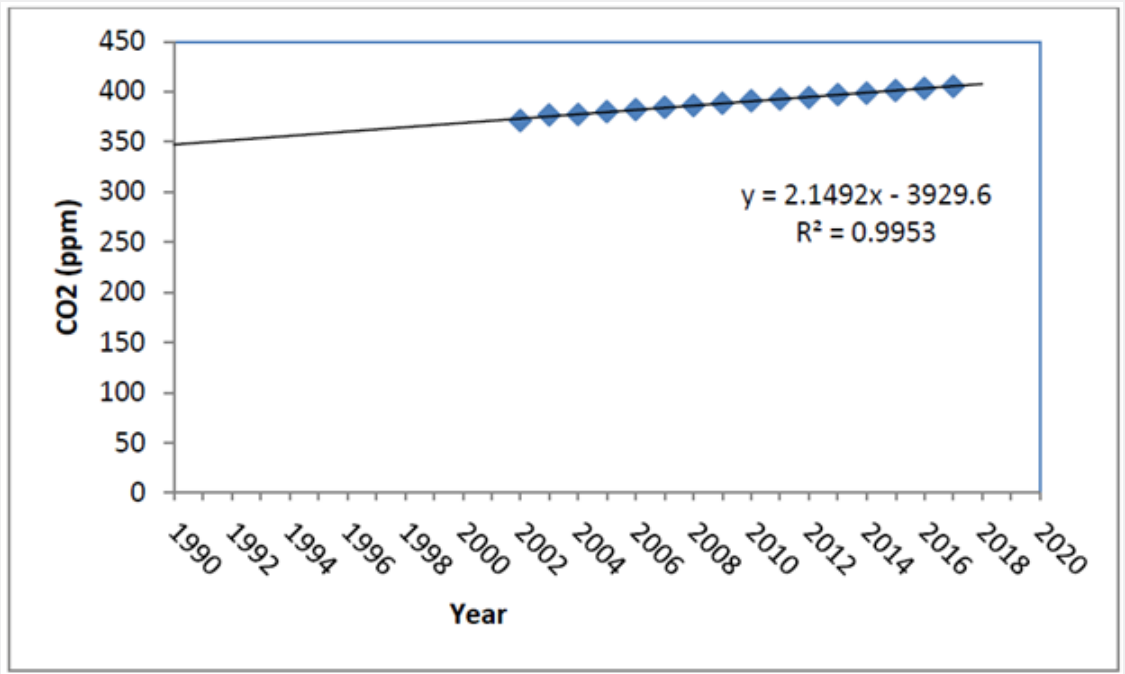

Figure 3: The annual average concentrations of carbon dioxide for Irbid city during the period 2002-2016.

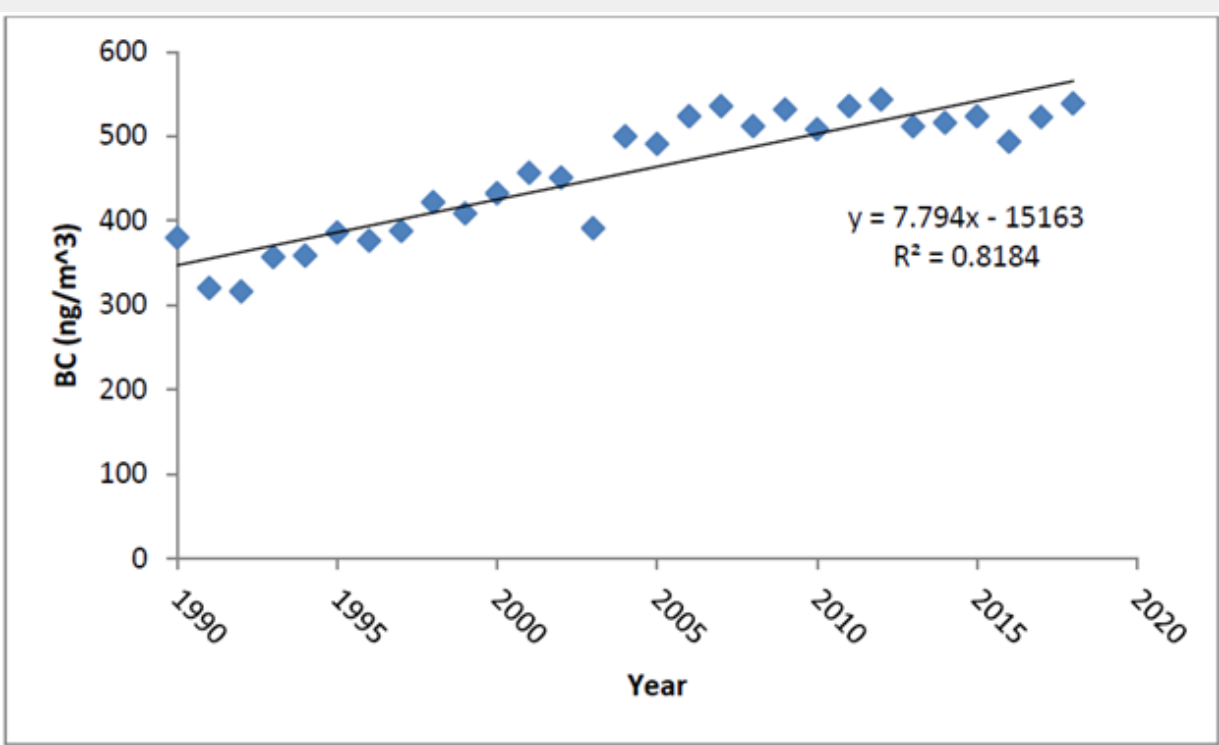

Figure 4: Black carbon mass concentration of Irbid city, north Jordan during the period 1990-2018

\section{Energy budget and BC during 1990-2018}

Energy budget and black carbon both had increasing trend over time during the period 1990 - 2018 as seen from Figure 2 \&
4. Black carbon affects both the atmosphere and the environment and it is considered to be an important climate issue because it is a strong absorber of radiation in the atmosphere. The increase of 
its concentrations leads to changes in the energy balance because it results in a strong radiative effect in both the upper atmosphere or on the surface of the earth. Although sources that produce black carbon produce other types of aerosols that play a role in cooling the atmosphere. The great crowding in these sources allows black carbon to dominate these types and thus reduces the net effect of climate that produces cooling. In fact, the black carbon interacts with these species so that its radiation absorption capacity becomes greater. One of the most important effects caused by black carbon is the direct radiative effect through the absorption and scattering of light, where the carbon absorption of radiation warms the atmosphere and reduces the solar radiation that reaches the surface and the reflected radiation that return to space. On the other hand, black carbon can be deposited on the surface through rain or it can mix with liquid clouds mixed with ice so that the surface reflection (albedo) is reduced. Since these influences directly contribute to energy balance, the relationship between them is explained based on these effects. As seen from Figure 5 there is a correlation between $\mathrm{BC}$ mass concentrations and SEB. SEB is increased when BC increased with a good correlation when $\mathrm{BC}<500 \mathrm{ng} / \mathrm{m}^{3}$.

Table 2: Annually surface energy budget for Irbid city during the years of 1990-2018.

\begin{tabular}{|c|c|c|c|c|c|c|c|c|c|c|}
\hline Year & $\alpha_{\mathrm{p}}$ & $1-\alpha_{p}$ & $\mathrm{~S}_{\text {in }}\left(\mathrm{W} / \mathrm{m}^{2}\right)$ & $S_{n}\left(W / m^{2}\right)$ & $\mathbf{L}_{\text {down }}\left(\mathrm{W} / \mathrm{m}^{2}\right)$ & $\underset{\left(W / \mathbf{m}^{2}\right)}{L_{u p}}$ & $\begin{array}{c}L_{n} \\
\left(W / m^{2}\right)\end{array}$ & $\underset{\left(W / m^{2}\right)}{R_{n}}$ & $\mathrm{SH}+\mathrm{LH}\left(\mathrm{W} / \mathrm{m}^{2}\right)$ & SEB $\left(W / m^{2}\right)$ \\
\hline 1990 & 0.3214 & 0.6786 & 255.14 & 173.14 & 322.78 & 411.23 & -88.45 & 84.69 & 85.33 & 0.64 \\
\hline 1991 & 0.3195 & 0.6805 & 244.47 & 166.36 & 329.19 & 410.68 & -81.49 & 84.87 & 85.41 & 0.54 \\
\hline 1992 & 0.3204 & 0.6796 & 247.67 & 168.31 & 320.58 & 404.84 & -84.26 & 84.05 & 84.66 & 0.61 \\
\hline 1993 & 0.3204 & 0.6796 & 261.12 & 177.45 & 321.02 & 410.84 & -89.82 & 87.63 & 88.28 & 0.65 \\
\hline 1994 & 0.3202 & 0.6798 & 250.96 & 170.59 & 328.57 & 414.05 & -85.48 & 85.11 & 85.71 & 0.6 \\
\hline 1995 & 0.3204 & 6796 & 261.43 & 177.66 & 320.38 & 411.08 & -90.7 & 86.96 & 87.6 & 0.64 \\
\hline 1996 & 0.3197 & 0.6803 & 250.03 & 170.1 & 328.33 & 414.77 & -86.43 & 83.67 & 84.29 & 0.62 \\
\hline 1997 & 0.311 & 0.689 & 246.38 & 169.75 & 324.47 & 407.32 & -82.85 & 86.9 & 87.57 & 0.67 \\
\hline 1998 & 0.3205 & 0.6795 & 259.21 & 176.13 & 327.38 & 415.86 & -88.48 & 87.65 & 88.28 & 0.63 \\
\hline 1999 & 0.3215 & 0.6785 & 257.2 & 174.52 & 323.3 & 416.77 & -93.56 & 80.96 & 81.57 & 0.61 \\
\hline 2000 & 0.3208 & 0.6792 & 255.24 & 173.36 & 323.97 & 414.14 & -90.18 & 83.18 & 83.82 & 0.64 \\
\hline 2001 & 0.3214 & 0.6786 & 257.22 & 174.55 & 325.03 & 417.46 & -92.43 & 82.12 & 82.76 & 0.64 \\
\hline 2002 & 0.3205 & 0.6795 & 252.68 & 171.65 & 328.23 & 416.86 & -88.64 & 83.01 & 83.72 & 0.71 \\
\hline 2003 & 0.3205 & 0.6795 & 249.42 & 169.49 & 328.83 & 415.91 & -87.08 & 82.41 & 83.07 & 0.66 \\
\hline 2004 & 0.3201 & 0.6799 & 253.76 & 172.53 & 337.48 & 428.03 & -90.54 & 81.99 & 82.64 & 0.65 \\
\hline 2005 & 0.3201 & 0.6799 & 255.33 & 173.59 & 324.9 & 413.6 & -88.7 & 84.89 & 85.57 & 0.68 \\
\hline 2006 & 0.3215 & 0.6785 & 245.1 & 166.29 & 323.45 & 408.3 & -84.85 & 81.44 & 82.05 & 0.61 \\
\hline 2007 & 0.3197 & 0.6803 & 250.41 & 170.35 & 329.2 & 412.17 & -82.97 & 87.38 & 87.98 & 0.6 \\
\hline 2008 & 0.321 & 0.679 & 265.61 & 180.36 & 325.93 & 414.94 & -89 & 91.36 & 91.99 & 0.63 \\
\hline 2009 & 0.3203 & 0.6797 & 259.04 & 176.07 & 329.58 & 414.59 & -85 & 91.07 & 91.7 & 0.63 \\
\hline 2010 & 0.3187 & 0.6813 & 255.39 & 173.99 & 333.43 & 422.61 & -89.17 & 84.82 & 85.48 & 0.66 \\
\hline 2011 & 0.32 & 0.68 & 254.01 & 172.71 & 324.46 & 408.69 & -84.23 & 88.48 & 89.13 & 0.65 \\
\hline 2012 & 0.3203 & 0.6797 & 253.01 & 171.97 & 334.81 & 420.51 & -85.7 & 86.27 & 87.03 & 0.76 \\
\hline 2013 & 0.3156 & 0.6844 & 257.74 & 176.41 & 324.37 & 412.35 & -87.99 & 88.42 & 89.12 & 0.7 \\
\hline 2014 & 0.3205 & 0.6795 & 253.34 & 172.14 & 328.16 & 416.8 & -88.64 & 83.5 & 84.31 & 0.81 \\
\hline 2015 & 0.3213 & 0.6787 & 249.15 & 169.11 & 340.64 & 419.71 & -79.07 & 90.04 & 90.91 & 0.87 \\
\hline 2016 & 0.3203 & 0.6797 & 254.6 & 173.04 & 334.23 & 418.5 & -84.28 & 88.76 & 89.59 & 0.83 \\
\hline 2017 & 0.3204 & 0.6796 & 261.09 & 177.44 & 338.18 & 425.18 & -87.01 & 90.43 & 91.31 & 0.88 \\
\hline 2018 & 0.3198 & 0.6802 & 266.48 & 181.27 & 345.23 & 426.36 & -81.13 & 100.14 & 101.1 & 0.96 \\
\hline
\end{tabular}




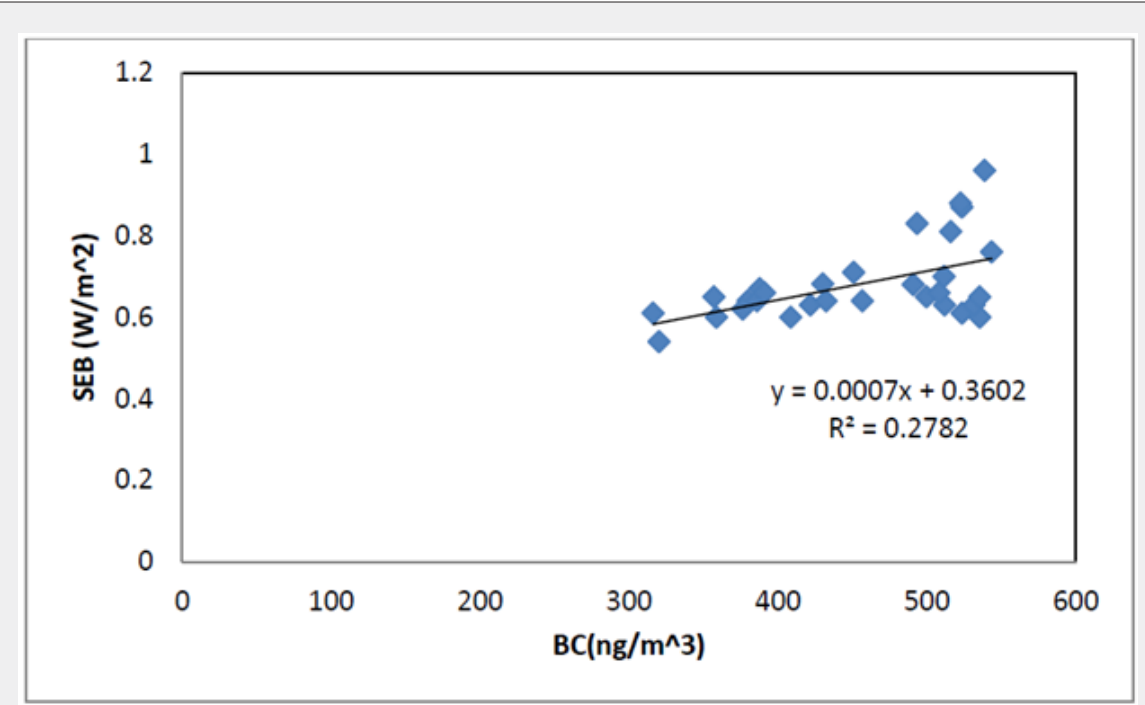

Figure 5: Correlation between BC mass concentration and SEB at Irbid city, north Jordan during the period 1990-2018.

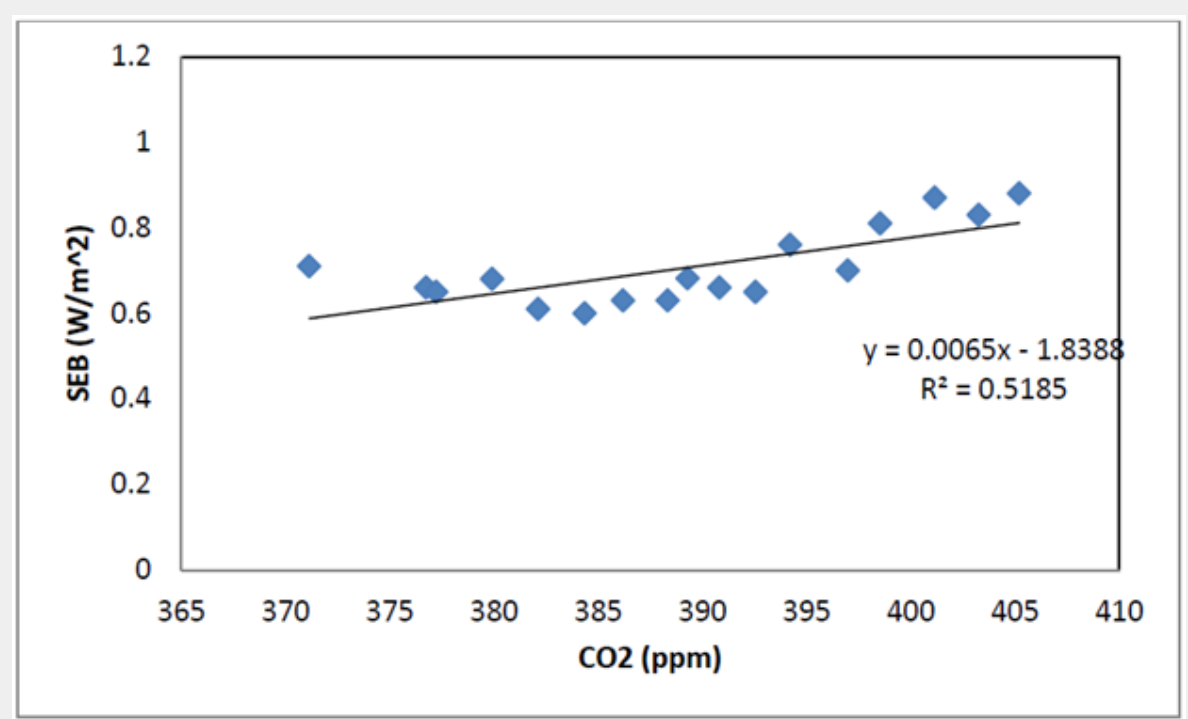

Figure 6: Correlation between CO2 and SEB at Irbid city, north Jordan during the period 1990-2018.

\section{Average Surface temperature of Irbid city during the period $1990-2018$}

Average annual surface temperatures for Irbid city, northern Jordan were collected during the period 1990 -2018 as presented in Figure 7. Temperatures have an increasing trends with slope equals $0.0539^{\circ} \mathrm{C} / \mathrm{yr}$ and $\mathrm{R}^{2}=0.15$. This means that there is an increase in the temperature for Irbid city. The temperature increased by about $1.51^{\circ} \mathrm{C}$ during the period from 1990 to 2018 , and it is expected that the increase will continue to reach $3.2^{\circ} \mathrm{C}$ by the end of 2050. This increase in temperature is an indicator of warming and change in SEB and thus climate change.

This increase in temperature for the study period is consistent with the increase in carbon dioxide and black carbon resulting from the increase in pollutants in the atmosphere. Carbon dioxide and black carbon are considered the most important absorbers of heat in the atmosphere, which directly and indirectly raise the air temperature.

\section{Conclusion}

The surface energy budget in north Jordan had nonzero values with increasing trends during the period of 1990 - 2018. The increase in the surface energy budget is mainly due to an increase in pollutants in the atmosphere. Carbon dioxide and black carbon were increasing during the same period (1990-2018). Carbon dioxide and black carbon are considered to be the most pollutants in the atmosphere that leads to an increase in the energy budget because both compounds are considered good absorbers of solar radiation. The increasing concentrations of carbon dioxide 
and black carbon were leading to an increase in atmospheric temperature. Also, the average annual temperature increased during the period of study. The energy budget plays an important role in stabilizing the climate, while any imbalance in the budget has a bad impact on the climate which is called climate change [15]. Now the effects of the climate change in north Jordan [16] were witnessed in terms of high temperatures, heat waves that not used to be in the past years in addition to sandstorms, and the amount of rain that falls in a short period of time which cause torrents. It is necessary now to pay attention to the causes of these pollutants. Human activities are the main reason that contributes to increasing the concentrations of carbon compounds in the atmosphere, which leads to energy imbalance. Carbon emissions and pollutants in the atmosphere can be reduced by shifting to the use of alternative energy and paying more attention to agriculture, in addition, to building green cities and also imposing strict environmental policies and restrictions on large industrial facilities that contribute to increasing pollution.

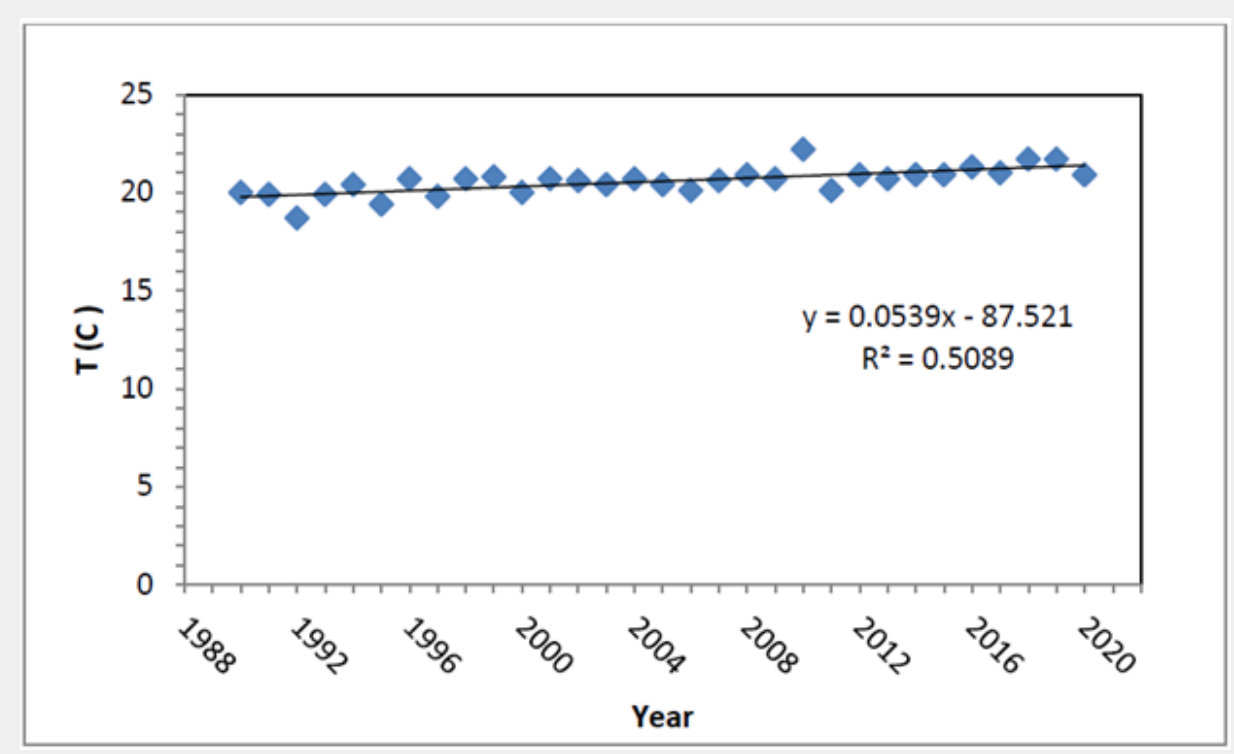

Figure 7: Average annual surface temperature of Irbid city, north Jordan during the period 1990-2020.

\section{Acknowledgment}

Analyses and visualizations used in this [study/paper/ presentation] were produced with the Giovanni online data system, developed and maintained by the NASA GES DISC.

\section{References}

1. Jax DW (1992) The Global Energy Budget. Science Activities 29(1): 2124.

2. Modest MF (2013) Radiative heat transfer. Academic press.

3. Günther M, Janotte N, Mezrhab A, Pottler K, Schillings C, et al. (2011) Solar radiation. Advanced CSP Teaching Materials, Enermena, pp. 2223

4. Trenberth KE, Fasullo JT, Kiehl J (2009) Earth's global energy budget. Bulletin of the American Meteorological Society 90: 311-323.

5. Lindsey R (2009) Climate and Earth's Energy Budget.

6. Stephens GL, Campbell GG, Haar TV (1981) Earth radiation budgets. Journal of Geophysical Research: Oceans 86(C10): 9739-9760.

7. Loeb NG, Thorsen TJ, Norris JR, Wang H, Su W (2018) Changes in earth's energy budget during and after the "pause" in global warming: an observational perspective. Climate 6(3): 62 .

8. Hofmann DJ, Butler JH, Dlugokencky EJ, Elkins JW, Masarie K, et al (2006) The role of carbon dioxide in climate forcing from 1979 to
2004: introduction of the Annual Greenhouse Gas Index. Tellus B: Chemical and Physical 63 Meteorology 58(5): 614-619.

9. Murphy DM, Solomon S, Portmann RW, Rosenlof KH, Forster PM, et al. (2009) An observationally based energy balance for the Earth since 950. Journal of Geophysical Research: Atmospheres 114(D17).

10. Jain PC (1993) Greenhouse effect and climate change: scientific basis and overview. Renewable energy 3(4-5): 403-420.

11. Casper JK (2010) Greenhouse gases: worldwide impacts. Infobase Publishing.

12. Trogler WC (1995) The environmental chemistry of trace atmospheric gases. J Chem Educ 72: 11.

13. Goosse H, PY Barriat, W Lefebvre, MF Loutre, V Zunz (2010) Introduction to climate dynamics and climate modeling.

14. Marshall J, Plumb RA (2008) Chapter 2: The global energy balance. Atmosphere, ocean, and climate dynamics: an introductory text, Elsevier Academic Press, pp. 9-22.

15. Hamdi MR, M Abu-Allaban, A Elshaieb, M Jaber, NM Momani (2009) Climate change in Jordan: a comprehensive examination approach. American Journal of Environmental Sciences 5(1): 740-750.

16. Lucke B, Z Al-Saad, M Schmidt, R Bäumler, S Lorenz, et al. (2008) Soils and Land Use in the Decapolis Region (Northern Jordan). Implications for Landscape Development and the Impact of Climate Change. Zeitschrift Des Deutschen Palästina-Vereins (1953) 124(2): 171-188. 
(C) This work is licensed under Creative (c) (i) Commons Attribution 4.0 License BY DOI:10.19080/IJESNR.2021.29.556260
Your next submission with Juniper Publishers will reach you the below assets

- Quality Editorial service

- Swift Peer Review

- Reprints availability

- E-prints Service

- Manuscript Podcast for convenient understanding

- Global attainment for your research

- Manuscript accessibility in different formats ( Pdf, E-pub, Full Text, Audio)

- Unceasing customer service

Track the below URL for one-step submission https://juniperpublishers.com/online-submission.php 